\title{
SERAPAN SENYAWA ORGANIK VOLATIL SEBAGAI BIOMARKER PENYAKIT KANKER PARU: SEBUAH MINI REVIEW
}

\section{ABSORPTION OF VOLATILE ORGANIC COMPOUNDS AS A LUNG CANCER'S BIOMARKER: A MINI REVIEW}

\author{
Donni Kis Apriyanto ${ }^{1}$, Mitrayana Mitrayana ${ }^{2}$ \\ ${ }^{1}$ Jurusan Fisika, Fakultas Matematika dan Ilmu Pengetahuan Alam, Universitas Lampung \\ ${ }^{2}$ Departemen Fisika, Fakultas Matematika dan Ilmu Pengetahuan Alam, Universitas Gadjah Mada, \\ Yogyakarta \\ Korespondensi: Donni Kis Apriyanto. Email: donni.kis@fmipa.unila.ac.id
}

\begin{abstract}
ABSTRAK
Ulasan ini merupakan hasil studi literatur yang memberikan tinjauan umum serapan senyawa-senyawa organik volatil yang dianggap sebagai biomarker kanker paru. Senyawa-senyawa ini dapat menyerap pada panjang gelombang tertentu. Senyawa-senyawa organik volatil yang teridentifikasi didaftar dan dijabarkan panjang gelombang yang dapat mereka serap. Studi literatur ini menyajikan kelompok senyawa-senyawa organik volatil dapat menyerap pada rentang panjang gelombang inframerah. Hasil ulasan ini mungkin dapat bermanfaat untuk pengembangan skrinning kanker paru dengan menggunakan alat spektroskopi fotoakustik yang menggunakan sumber laser pada rentang panjang gelombang inframerah atau ultraviolet dengan memanfaatkan serapan panjang gelombang oleh senyawa-senyawa tertentu.
\end{abstract}

Keyword: Biomarker Kanker Paru, Senyawa Organik Volatil, Spektroskopi

\begin{abstract}
This review is the result of a literature study that provides a general collection of volatile organic compounds (VOC) which are considered as markers for lung cancer. These compounds can absorb certain long waves. The volatile organic compounds identified are listed and described in wavelengths that they can absorb. Literature studies that produce volatile organic compounds in the analysis wavelength range. The results of this review may be useful for the development of lung cancer screening by photoacoustic spectroscopic devices that use laser sources in the range of infrared or ultraviolet wavelengths by utilizing wavelength absorb by certain compounds.
\end{abstract}

Keyword: Lung Cancer Biomarker, Volatile Organic Compounds, Spectroscopy

How To Cite: Apriyanto, D., \& Mitrayana, M. (2020). SERAPAN SENYAWA ORGANIK VOLATIL SEBAGAI BIOMARKER PENYAKIT KANKER PARU: SEBUAH MINI REVIEW. Biomedika, 12(2), 58-64. doi:https://doi.org/10.23917/biomedika.v12i2.10114

DOI: https://doi.org/10.23917/ biomedika.v12i2.10114 


\section{PENDAHULUAN}

Kanker merupakan kelompok besar penyakit yang dapat menyerang bagian tubuh manapun dan merupakan penyebab kematian nomor dua di dunia. Menurut data WHO ( 2018) 1,76 juta kasus kematian diakibatkan kanker paru dari 9,6 juta kasus kematian karena kanker secara umum. Kanker paru merupakan penyumbang tertinggi kejadian kanker pada laki-laki di Indonesia. Angka kejadian penyakit kanker di Indonesia berada pada urutan 8 di Asia Tenggara dengan angka kejadian rata-rata kematian $\quad 10,9 / 100.000$ penduduk laki-laki (Kementrian Kesehatan (Kemkes) RI, 2019).

Penyebab utama dari tingginya tingkat kematian akibat kanker paru adalah terlambat dalam mendiagnosis penyakit. Oleh karena itu, sangat penting dalam mendiagnosa penyakit kanker paru sejak dini (Saalberg and Wolff, 2016). Penegakan diagnosis kanker paru membutuhkan keterampilan dan sarana yang tidak sederhana dan memerlukan pendekatan yang erat dan kerja sama multidisiplin. Penemuan kanker paru pada stadium dini akan sangat membantu penderita, dan penemuan diagnosis dalam waktu yang lebih cepat memungkinkan penderita memperoleh kualitas hidup yang lebih baik.

Salah satu metode yang sedang dikembangkan dalam mendeteksi berbagai penyakit adalah analisis gas hembus napas. Hal ini dikaitkan dengan sifatnya yang non-invasive, mendapatkan sampel yang mudah dan potensi dalam memfasilitasi untuk mempercepat diagnosis (Lawal et al., 2017). Perkembangan analisis gas hembus napas sangat menjanjikan dalam biomarker kanker didasarkan pada volatolomik, yaitu pada analisis senyawa organik yang mudah menguap (semi-volatile dan sangat volatile) yang berasal dari sel kanker dan/atau lingkungan mikro sel kanker yang dapat dideteksi dalam cairan tubuh yang berbeda (gas hembus napas, darah, urin, keringat, dan lain-lain) tergantung pada jaringan/darah dan koefisien partisi darah/udara (Einoch Amor et al., 2019). Horyáth et al. (2009) meninjau bukti ilmiah yang menunjukkan bahwa tanda kimia yang unik dapat dideteksi dalam napas pasien dengan kanker paru-paru dan profil biomarker napas yang dihembuskan dapat membantu pengambilan keputusan klinis.

Senyawa-senyawa organik volatil dalam gas hembus napas tersedia dalam jumlah yang 
sangat sedikit dari ppm hingga ppb. Metode yang pernah dilakukan untuk mendeteksi kandungan gas hembus nafas pada pasien kanker paru yaitu dengan spektrometer massa reaksi transfer proton (proton transfer reaction mass spectrometry (PTR-MS)) dan spektrometer massa kromatografi gas - mikroekstraksi fase solid (solid phase microextraction - gas chromatography mass spectrometry (SPMEGCMS)). Namun SPME-GCMS ini relatif tidak sensitif karena komponen-komponen penanda penyakit kanker paru dalam gas hembus nafas pada relawan sehat tidak terdeteksi. Kekurangan lain, pada PTR-MS yaitu tidak bisa mengidentifikasi senyawa dengan pasti (Bajtarevic et al., 2009). Oleh karena itu diperlukan alat yang mampu mendeteksi senyawa organik volatil dengan sensitifitas yang tinggi. Salah satunya adalah spektroskopi fotoakustik laser $\mathrm{CO}_{2}$. Penelitian untuk menguji performa spektrometer fotoakustik laser $\mathrm{CO}_{2}$ dalam menganalisis konsentrasi senyawasenyawa dalam gas hembus napas seperti penelitian yang dilakukan peneliti sebelumnya pada penderita diabetes (Tyas et al., 2018) dan penderita kanker paru (Mitrayana et al., 2020).
Tujuan penelitian ini diharapkan dapat dijadikan sebagai acuan dalam mendeteksi penyakit kanker paru dengan menganalisis gas hembus napas menggunakan spektrometer fotoakustik dengan sumber laser pada rentang panjang gelombang infrared, cahaya tampak atau ultraviolet. Selain itu penelitian ini dimungkinkan juga sebagai acuan analisis gas dengan menggunakan alat lain yang menggunakan prinsip penyerapan gelombang oleh gas.

\section{METODE}

Penelitian ini menggunakan metode studi literatur dengan artikel atau penelitian yang berhubungan dengan senyawa organik volatil sebagai biomarker penyakit paru. Senyawasenyawa organik volatil yang diambil adalah senyawa-senyawa yang dideteksi menggunakan (Gas Chromatography Mass Spectrometry (GCMS), (Proton Transfer Reaction - Mass Spectrometry (PTR-MS) dan hidung elektronik (electronic nose). Data senyawa-senyawa yang didapatkan tersebut dicari nilai serapan panjang gelombang dengan studi literatur. Hasil yang didapat akan dikelompokkan terhadap senyawasenyawa yang dapat menyerap panjang 
gelombang infrared, cahaya tampak atau ultraviolet.

\section{HASIL DAN PEMBAHASAN}

Saalberg and Wolf (2016) mengumpulkan senyawa-senyawa organik volatil yang dapat digunakan sebagai biomarker kanker paru.
Tujuh puluh tujuh senyawa telah diidentifikasi dengan 30 senyawa organik volatil diantaranya ditemukan sebagai biomarker kanker paru oleh lebih dari satu penelitian. Senyawa organik volatil tersebut yang diteliti menggunakan deteksi GCMS, SPME-GC dan SPME-GCMS disajikan pada tabel 1.

Tabel 1. Senyawa-senyawa organik volatile biomarker kanker paru

\begin{tabular}{|c|c|c|c|}
\hline No. & VOC & Rumus Senyawa & Teknik Deteksi \\
\hline 1 & 2-Butanona (Metil etil keton) & $\mathrm{C}_{2} \mathrm{H}_{5} \mathrm{COCH}_{3}$ & SPME-GCMS, GCMS \\
\hline 2 & 1-propanol & $\mathrm{CH}_{3} \mathrm{CH}_{2} \mathrm{CH}_{2} \mathrm{OH}\left(\mathrm{C}_{3} \mathrm{H}_{8} \mathrm{O}\right)$ & SPME-GCMS \\
\hline 3 & Isoprena (2-metil-1,3-butadin) & $\mathrm{CH}_{2}=\mathrm{CHC}\left(\mathrm{CH}_{3}\right)=\mathrm{CH}_{2}$ & SPME-GCMS, SPME-GC \\
\hline 4 & Etilbenzena & $\mathrm{C}_{6} \mathrm{H}_{5} \mathrm{C}_{2} \mathrm{H}_{5}$ & SPME-GCMS, GCMS \\
\hline 5 & Stirena (Etenilbenzena) & $\mathrm{C}_{6} \mathrm{H}_{5} \mathrm{CH}=\mathrm{CH}_{2}\left(\mathrm{C}_{8} \mathrm{H}_{8}\right)$ & SPME-GC, GCMS, SPME-GCMS \\
\hline 6 & Heksanal & $\mathrm{CH}_{3}\left(\mathrm{CH}_{2}\right)_{4} \mathrm{CHO}$ & SPME-GC, SPME-GCMS \\
\hline 7 & Asetone (Propanon) & $\mathrm{CH}_{3} \mathrm{COCH}_{3}$ & SPME-GCMS, GCMS \\
\hline 8 & 2-pentanona (Metil propil keton) & $\mathrm{CH}_{3} \mathrm{COCH}_{2} \mathrm{CH}_{2} \mathrm{CH}_{3}$ & GCMS, SPME-GCMS \\
\hline 9 & $\begin{array}{l}\text { 2-propanol (Isopropilalkohol, } \\
\text { Isopropanol) }\end{array}$ & $\left(\mathrm{CH}_{3}\right)_{2} \mathrm{CHOH}$ & GCMS, SPME-GCMS \\
\hline 10 & Dekana & $\mathrm{CH}_{3}\left(\mathrm{CH}_{2}\right)_{8} \mathrm{CH}_{3}$ & SPME-GC, GCMS, SPME-GCMS \\
\hline 11 & Benzena & $\mathrm{C}_{6} \mathrm{H}_{6}$ & SPME-GC, GCMS, SPME-GCMS \\
\hline 12 & Heptanal & $\mathrm{CH}_{3}\left(\mathrm{CH}_{2}\right)_{5} \mathrm{CHO}$ & SPME-GC, SPME-GCMS \\
\hline 13 & Butana & $\mathrm{CH}_{3} \mathrm{CH}_{2} \mathrm{CH}_{2} \mathrm{CH}_{3}$ & SPME-GCMS, GCMS \\
\hline 14 & Propanal & $\mathrm{CH}_{3} \mathrm{CH}_{2} \mathrm{CHO}$ & SPME-GCMS \\
\hline 15 & n-pentana & $\mathrm{CH}_{3}\left(\mathrm{CH}_{2}\right)_{3} \mathrm{CH}_{3}$ & SPME-GCMS, GCMS \\
\hline 16 & Benzaldehida & $\mathrm{C}_{6} \mathrm{H}_{5} \mathrm{CHO}$ & SPME-GCMS \\
\hline 17 & Butanal (Butiraldehida) & $\mathrm{CH}_{3} \mathrm{CH}_{2} \mathrm{CH}_{2} \mathrm{CHO}$ & SPME-GCMS, GCMS \\
\hline 18 & Undekana & $\mathrm{CH}_{3}\left(\mathrm{CH}_{2}\right)_{9} \mathrm{CH}_{3}$ & GCMS \\
\hline 19 & Propil benzena & $\mathrm{C}_{6} \mathrm{H}_{5} \mathrm{CH}_{2} \mathrm{CH}_{2} \mathrm{CH}_{3}$ & GCMS \\
\hline 20 & 1,2,4-trimetil benzena & $\mathrm{C}_{6} \mathrm{H}_{3}\left(\mathrm{CH}_{3}\right)_{3}$ & SPME-GCMS \\
\hline 21 & Metil siklopentana & $\mathrm{C}_{5} \mathrm{H}_{9} \mathrm{CH}_{3}$ & GCMS \\
\hline 22 & 3-hidroksi-2-butanon (Asetoin) & $\mathrm{CH}_{3} \mathrm{COCH}(\mathrm{OH}) \mathrm{CH}_{3}$ & SPME-GCMS \\
\hline 23 & Pentanal & $\mathrm{CH}_{3}\left(\mathrm{CH}_{2}\right)_{3} \mathrm{CHO}$ & SPME-GCMS \\
\hline 24 & Octanal & $\mathrm{CH}_{3}\left(\mathrm{CH}_{2}\right)_{6} \mathrm{CHO}$ & SPME-GCMS \\
\hline 25 & Nonanal & $\mathrm{CH}_{3}\left(\mathrm{CH}_{2}\right)_{7} \mathrm{CHO}$ & SPME-GCMS \\
\hline 26 & Dimetil sulfida & $\left(\mathrm{CH}_{3}\right)_{2} \mathrm{~S}$ & SPME-GCMS \\
\hline
\end{tabular}




$\begin{array}{llll}27 & \text { 4-metil oktana } & \mathrm{C}_{9} \mathrm{H}_{20} & \text { GCMS } \\ 28 & \text { Propana } & \mathrm{CH}_{3} \mathrm{CH}_{2} \mathrm{CH}_{3} & \text { SPME-GCMS } \\ 29 & \text { Isoheksana (2-metil pentana) } & \mathrm{CH}_{3} \mathrm{CH}_{2} \mathrm{CH}_{2} \mathrm{CH}\left(\mathrm{CH}_{3}\right)_{2} & \text { SPME-GCMS } \\ 30 & \text { Heptana } & \mathrm{CH}_{3}\left(\mathrm{CH}_{2}\right)_{5} \mathrm{CH}_{3} & \text { SPME-GCMS }\end{array}$

Senyawa organik seperti hidrokarbon rendah $\left(\mathrm{C}_{2} \mathrm{H}_{4}, \mathrm{C}_{\mathrm{x}} \mathrm{H}_{\mathrm{x}}\right)$ dan aldehida dan keton (komponen C-H dengan setidaknya memiliki satu ikatan rangkap C-O) berada pada rentang energi $2600 \mathrm{~cm}^{-1}$ dan $3200 \mathrm{~cm}^{-1}$ (Grosch, 2014). Selain pada rentang tersebut, serapan keton juga dapat berada pada rentang $700 \mathrm{~cm}^{-1}-1780 \mathrm{~cm}^{-1}$ (Harrison et al., 2011). Beberapa senyawa organik berada pada rentang energi inframerah dan ultraviolet seperti yang disajikan pada tabel 2 .

Tabel 2. Daerah serapan senyawa-senyawa organik volatile biomarker kanker paru

\begin{tabular}{llll}
\hline No. & \multicolumn{1}{c}{ VOC } & \multicolumn{1}{c}{ Rumus Senyawa } & \multicolumn{1}{c}{ Rentang serapan $\left(\mathbf{c m}^{-1}\right)$} \\
\hline 1 & $\begin{array}{l}\text { 2-Butanon (Metil etil } \\
\text { keton) }\end{array}$ & $\mathrm{C}_{2} \mathrm{H}_{5} \mathrm{COCH}_{3}$ & $550-6500$ (Sharpe et al., 2004) \\
2 & $\begin{array}{l}\text { Isoprena (2-metil-1,3- } \\
\text { butadin) }\end{array}$ & $\mathrm{CH}_{2}=\mathrm{CHC}\left(\mathrm{CH}_{3}\right)=\mathrm{CH}_{2}$ & $600-6500$ (Sharpe et al., 2004) \\
3 & Etilbenzena & $\mathrm{C}_{6} \mathrm{H}_{5} \mathrm{C}_{2} \mathrm{H}_{5}$ & $600-6500$ (Sharpe et al., 2004) \\
4 & Aseton (Propanon) & $\mathrm{CH}_{3} \mathrm{COCH}_{3}$ & $700-1780$ (Harrison et al., 2011) \\
5 & Benzena & $\mathrm{C}_{6} \mathrm{H}_{6}$ & $600-6500$ (Rinsland et al., 2008) \\
& & & $36990-41785$ (Fally et al., 2009) \\
6 & Benzaldehida & $\mathrm{C}_{6} \mathrm{H}_{5} \mathrm{CHO}_{2}$ & $600-6500$ (Sharpe et al., 2004) \\
7 & Dimetil sulfida & $\left(\mathrm{CH}_{3}\right)_{2} \mathrm{~S}_{2}$ & $600-6500$ (Sharpe et al., 2004) \\
8 & Propana & $\mathrm{CH}_{3} \mathrm{CH}_{2} \mathrm{CH}_{3}$ & $600-6500$ (Sharpe et al., 2004) \\
& & & $2540-3300$ (Harrison and Bernath, \\
\hline
\end{tabular}

Rentang serapan pada tabel 2 dapat dibedakan menjadi 2 golongan, yaitu rentang energi pada serapan inframerah $(100$ $\mathrm{cm}^{-1}$ sampai $10.000 \mathrm{~cm}^{-1}$ ) (Silverstein et al., 1949) dan rentang energi pada serapan ultraviolet. Senyawa-senyawa organik volatil pada tabel 2, seluruhnya dapat menyerap pada rentang inframerah baik inframerah dekat sampai inframerah jauh, sehingga senyawa-senyawa tersebut dapat dideteksi menggunakan spektrometer dengan sumber laser pada rentang panjang 
gelombang inframerah. Selain menyerap pada rentang panjang gelombang infrared, senyawa pada tabel 2 juga ada yang menyerap pada rentang ultraviolet misalnya benzena, sehingga senyawa ini dapat digunakan pada spektrometer dengan sumber laser pada rentang panjang gelombang ultraviolet.

\section{SIMPULAN}

Senyawa-senyawa organik volatil yang dapat digunakan sebagai biomarker kanker paru dapat menyerap pada rentang panjang gelombang inframerah sehingga senyawasenyawa ini dapat dideteksi dengan menggunakan spektrometer dengan sumber laser inframerah. Senyawa yang juga dapat dideteksi oleh spektrometer dengan sumber laser ultraviolet yaitu benzena.

\section{DAFTAR PUSTAKA}

Bajtarevic, A. Ager, C., Pienz, M., Klieber, M., Schwarz, K., Ligor, M., Ligor, T., Filipiak, W., Denz, H., Fiegl, M., Hilbe, W., Weiss, W., Lukas, P., Jamnig, H., Hackl, M., Haidenberger, A., Buszewski, B., Miekisch, W., Schubert, J., and Amann, A. 2009. Noninvasive detection of lung cancer by analysis of exhaled breath. BMC Cancer, 9, p. 348. doi: 10.1186/1471-2407-9-348.

Einoch Amor, R. Nakhleh, M.K., Barash, O., and Haick, H. 2019. Breath analysis of cancer in the present and the future. European respiratory review: an official journal of the European Respiratory Society, 28(152). Pp: 1-10. doi: 10.1183/16000617.0002-2019.

Fally, S., Carleer, M. and Vandaele, A. C. 2009. UV Fourier transform absorption cross sections of benzene, toluene, meta-, ortho-, and para-xylene. Journal of Quantitative Spectroscopy and Radiative Transfer. 110(9-10), Pp: 766-82. doi: 10.1016/j.jqsrt.2008.11.014.

Grosch, H. 2014. Optical Absorption Spectroscopy for Gas Analysis in Biomass Gasification. Danmarks Tekniske Universitet (DTU).

Harrison, J.J. Humpage, N., Allen, N.D.C., Waterfall, A.M., Bernath, P.F., and Remedios, J.J. 2011. Mid-infrared absorption cross sections for acetone (propanone). Journal of Quantitative Spectroscopy and Radiative Transfer. Elsevier, 112(3). Pp: 457-64. doi: 10.1016/j.jqsrt.2010.09.002.

Harrison, J. J. and Bernath, P. F. 2010. Infrared absorption cross sections for propane $(\mathrm{C} 3 \mathrm{H} 8)$ in the $3 \mu \mathrm{m}$ region. Journal of Quantitative Spectroscopy and Radiative Transfer. Elsevier, 111(9). Pp: 1282-1288. doi: 10.1016/j.jqsrt.2009.11.027.

Horváth, I. Lázár, Z., Gyulai, N., Kollai, M., Losonczy, G. 2009. Exhaled biomarkers in lung cancer. European Respiratory Journal, 34(1). Pp: 261-75. doi: 10.1183/09031936.00142508.

Kementrian Kesehatan (Kemkes) RI. 2019. Available at: http://www.depkes.go.id/article/view/1 9020100003/hari-kanker-sedunia2019.html (Accessed: 29 July 2019). 
Lawal, O. Ahmed, W. M., Nijsen, T. M. E., Goodacre, R., \& Fowler, S. J. 2017. Exhaled breath analysis: a review of "breath-taking" methods for off-line analysis. Metabolomics. Springer US, 13(10). Pp: 1-16. doi: 10.1007/s11306017-1241-8.

Mitrayana, Apriyanto, D. K. and Satriawan, M. 2020. CO2 Laser Photoacoustic Spectrometer for Measuring Acetone in the Breath of Lung Cancer Patients', Biosensors. 10 . p. 55. doi: 10.3390/bios 10060055 .

Rinsland, C. P. Devi, V., Blake, T., Sams, R., Sharpe, S., and Chiou, L. 2008. Quantitative measurement of integrated band intensities of benzene vapor in the mid-infrared at 278, 298, and $323 \mathrm{~K}$. Journal of Quantitative Spectroscopy and Radiative Transfer. 109(15). Pp: 2511-22.

10.1016/j.jqsrt.2008.04.007.

Saalberg, Y. and Wolff, M. 2016. VOC breath biomarkers in lung cancer. Clinica Chimica Acta. Elsevier B.V. 459. Pp. 5-9. doi: 10.1016/j.cca.2016.05.013
Sharpe, S. W., Johnson, T. J., Sams, R. L., Chu, P. M., Rhoderick, G. C., \& Johnson, P. A. 2004. Gas-Phase Databases for Quantitative Infrared Spectroscopy. Applied Spectroscopy. 58(12). Pp: 1452-61. doi: 10.1366/0003702042641281.

Silverstein, R. M., Webster, F. X. and Kiemle, D. J. 1949. Spectrometric Identification of Organic Compounds. $7^{\text {th }}$ edition. New York: John Wiley \& Sons, Inc. doi: 10.1021/ac60028a006.

Tyas, F. H. Nikita, J.G., Apriyanto, D.K., Mitrayana and Amin, M.N. 2018. The Performance of $\mathrm{CO} 2$ Laser Photoacoustic Spectrometer in Concentration Acetone Detection As Biomarker for Diabetes Mellitus Type 2. Journal of Physics: Conference Series. doi: 10.1088/17426596/1011/1/012056.

World Health Organization (WHO). 2018. Cancer. Available at: https://www.who.int/en/newsroom/fact-sheets/detail/cancer (Accessed: 29 July 2019). 